\title{
Immunomodulatory effects of whole yeast cells and capsicum in weanling pigs challenged with pathogenic Escherichia coli ${ }^{1}$
}

\author{
Samantha J. Wojnicki, ${ }^{\dagger}$ Antrison Morris, ${ }^{\dagger}$ Brooke Nicole Smith,${ }^{\dagger}$ Carol W. Maddox,,${ }^{\dagger}$ and \\ Ryan Neil Dilger ${ }^{\dagger, 2,}$
}

${ }^{\dagger}$ Department of Animal Sciences, University of Illinois, Urbana, IL 61801; and "Department of Pathobiology, University of Illinois, Urbana, IL 61801

\begin{abstract}
An experiment was conducted to evaluate growth performance, fecal bacterial counts, frequency of diarrhea, and clinical blood parameters in weanling pigs inoculated with enterotoxigenic Escherichia coli (ETEC) who were fed a whole yeast cell (WYC) product and capsicum, a plant essential oil. Weanling pigs (34 barrows and 30 gilts, $21 \mathrm{~d}$ of age, $5.90 \pm 1.03 \mathrm{~kg} \mathrm{BW})$ were allotted to experimental treatments in a randomized complete block design based on litter, sex, and initial BW. Four pigs were individually housed within each containment chamber and assigned to 1 of 4 dietary treatments, which included a control diet without or with $0.2 \%$ WYC (CitriStim; ADM, Decatur, IL) or 10 ppm of capsicum (XTract 6933; Pancosma, Geneva, Switzerland), provided either alone or in combination. After receiving diets for $13 \mathrm{~d}$, pigs were orally inoculated with $\mathrm{F} 18^{+}$ETEC and maintained on their assigned diets for an additional $10 \mathrm{~d}$; a separate cohort of 12 pigs receiving the control diet was sham-inoculated using PBS. Body and feeder weights were recorded, and fecal swabs collected, on 0,5 , and $10 \mathrm{~d}$ postinoculation

(DPI), with blood sampled at $0,2,7$, and 10 DPI for isolation of peripheral blood mononuclear cells. Pigs challenged with ETEC and fed diets containing WYC or capsicum alone had a higher frequency of diarrhea when compared with pigs receiving diets without those compounds $(P<0.05)$. Total fecal bacterial counts in pigs fed the combination of additives were highest when compared with either additive alone (interaction, $P=0.03$ ) at $10 \mathrm{DPI}$. Blood leukocyte counts were increased in challenged pigs receiving the combination of additives compared with all other challenged treatment groups (interaction, $P=0.04$ ). The addition of WYC increased (main effect, $P=0.01)$ lymphocyte counts at 7 DPI. Proportions of $\mathrm{CD}^{+}$and $\mathrm{CD} 4^{+} \mathrm{CD} 8^{+}$cells were lower in pigs fed the combination of additives compared with pigs fed either additive alone at 0 and 7 DPI. In conclusion, these data indicate that the combination of the 2 additives elicited higher ETEC shedding and circulating leukocyte counts, and reduced the proportions of cytotoxic and memory T-cells than either additive alone.
\end{abstract}

Key words: Escherichia coli, essential oil, immunity, pig, yeast

(C) The Author (s) 2019. Published by Oxford University Press on behalf of the American Society of Animal Science. All rights reserved. For permissions, please e-mail: journals.permissions@oup.com.

J. Anim. Sci. 2019.97:1784-1795 doi: 10.1093/jas/skz063

\section{INTRODUCTION}

Enterotoxigenic Escherichia coli (ETEC) infection in weanling pigs is a major problem

${ }^{1}$ Financial support from Archer Daniels Midland (Decatur, IL) is greatly appreciated.

${ }^{2}$ Corresponding author: rdilger2@illinois.edu

Received December 3, 2018.

Accepted February 8, 2019. for producers due to economic losses caused by morbidity, mortality, and reduced growth performance (Fairbrother et al., 2005). Pathogenic challenges, such as with ETEC infections, may cause reductions in growth performance, due partly 
to nutrients and energy being diverted away from growth and towards immune-related processes (Spurlock, 1997). Typically, antibiotics are used to minimize incidence and severity of ETEC infection in newly weaned pigs, but congruent with judicious use of antibiotics in food-producing animals, a search for alternative or complementary strategies to combat bacterial infections and alter immune responses is ongoing (Le Bon et al., 2010).

Both prebiotics and essential oils have been shown to reduce the inflammatory response and alleviate detrimental effects either through the production of short-chain fatty acids (SCFA) from microbial fermentation of prebiotics or the inhibition of pro-inflammatory cytokines and decreased white blood cell levels as purported for essential oils (Yaqoob and Calder, 2011; Liu et al., 2012; Vieira et al., 2013). Receptors for SCFA on immune cells, such as eosinophils and neutrophils, may help strengthen the immune response, contributing to the immunomodulatory effects of prebiotics (Maslowski et al., 2009; Kim et al., 2013). Essential oils have previously been shown to increase growth performance and reduce incidence of diarrhea in pigs (Shoba and Thomas, 2001; Liu et al., 2013). Both prebiotics and essential oils have the potential to replace in-feed antibiotics used to lessen the effects of ETEC infection, though their effects on the immune system have been varied, and the combination of these 2 additives has yet to be fully elucidated. Thus, we conducted an experiment to evaluate the combined effects of a whole yeast cell (WYC) product (CitriStim; ADM, Decatur, IL) and a plant essential oil (capsicum, encapsulated; XTract 6933; Pancosma, Geneva, Switzerland) on growth performance, frequency of diarrhea, fecal bacterial counts, and blood clinical outcomes in weanling pigs experimentally challenged with ETEC.

\section{MATERIALS AND METHODS}

All animal care and experimental procedures were approved by the Institutional Animal Care and Use Committee and the Institutional Biosafety Committee at the University of Illinois before initiation of the experiment.

\section{Animal Husbandry}

A total of 64 weaned pigs (21 d of age) originating from PIC 359 (Pig Improvement Company, Hendersonville, TN) boars mated with Fertilis-25 females (Genetiporc, Alexandria, MN) were used in a single experiment with 2 cohorts of pigs (32 pigs per cohort) and all data analyzed together. Although pigs enrolled on this study were not individually genotyped for ETEC susceptibility ahead of study enrollment, pigs from this same herd were previously proven to be susceptible to ETEC (data not shown), and no gilts or sows in that herd received $E$. coli vaccinations. A total of 34 barrows and 30 gilts (initial BW $5.91 \pm 1.03 \mathrm{~kg}$ ) were selected and allotted to experimental treatments in a randomized complete block design based on initial BW, litter, and sex. Pigs were housed in the Edward R. Madigan Laboratory (ERML) large animal biocontainment facility at the University of Illinois. A suite of 8 chambers was used to house both the challenged and unchallenged (sham-inoculated) pigs, and strict biosecurity measures were followed to prevent cross-contamination. Each chamber consisted of 4 individual pens $\left(0.84 \mathrm{~m}^{2}\right)$ each equipped with a nipple drinker and a feeder, allowing pigs to be individually housed.

Four diets were prepared from a common basal (Table 1) in a $2 \times 2+1$ factorial arrangement. Diet 1 (negative control) was a nursery diet formulated to meet or exceed NRC (2012) requirements for weanling pigs; this diet did not contain antibiotics, spray-dried plasma, or zinc oxide as growth-promoting or prophylactic agents. Diet 2 was formulated as diet 1, but was supplemented with $0.2 \%$ WYC (CitriStim; ADM, Decatur, IL). Diet 3 was formulated as diet 1, but was supplemented with an essential oil (capsicum, encapsulated, $10 \mathrm{ppm}$; XTract 6933; Pancosma, Geneva, Switzerland) and diet 4 was formulated as diet 1, but was supplemented with both WYC $(0.2 \%)$ and capsicum (10 ppm). Neither WYC nor capsicum replaced another ingredient in the formulation (i.e., test articles added on top of the control formulation, but each product was physically mixed into the final diets) and pigs remained on the same diet, fed in mash form, throughout the study.

Upon arrival, pigs were allotted to 1 of 5 experimental groups. Treatment 1 was the control group, fed diet 1 , and without $E$. coli challenge. The rest of the treatments were challenged with ETEC and fed 1 of 4 treatment diets described above.

\section{Enterotoxigenic E. coli Challenge}

The pathogenic E. coli (isolate number UI-VDL 05-27242) was an F18-fimbriated $E$. coli strain that produces heat-labile toxin, heat stable toxin b, and Shiga-like toxin 2 (Almeida et al., 2014). Pigs were orally inoculated with $E$. coli $\left(10^{10} \mathrm{CFU}\right.$ per 
Table 1. Ingredient and nutrient composition of the control diet fed to weanling pigs

\begin{tabular}{|c|c|}
\hline Ingredient, $\%$ of diet & Value $^{1}$ \\
\hline Corn & 39.17 \\
\hline Dried whey permeate $^{2}$ & 23.99 \\
\hline Soybean meal & 15.05 \\
\hline Fish meal $^{3}$ & 10.00 \\
\hline Processed soy product ${ }^{4}$ & 6.00 \\
\hline Dried whey & 3.50 \\
\hline Limestone & 0.70 \\
\hline Monocalcium phosphate & 0.60 \\
\hline L-Lysine $\mathrm{HCl}$ & 0.32 \\
\hline DL-Methionine & 0.06 \\
\hline L-Threonine & 0.21 \\
\hline Vitamin premix ${ }^{5}$ & 0.30 \\
\hline Mineral premix ${ }^{6}$ & 0.10 \\
\hline \multicolumn{2}{|c|}{ Calculated composition (as-is basis) } \\
\hline $\mathrm{ME}, \mathrm{kcal} / \mathrm{kg}$ & 3,561 \\
\hline Lactose, $\%$ & 23.41 \\
\hline Ether extract, $\%$ & 3.60 \\
\hline Crude fiber, $\%$ & 1.13 \\
\hline Calcium, $\%$ & 1.08 \\
\hline Phosphorus (total), $\%$ & 0.83 \\
\hline \multicolumn{2}{|l|}{ SID amino acids, $\%$} \\
\hline Lys & 1.31 \\
\hline Ile & 0.71 \\
\hline Leu & 1.40 \\
\hline Met & 0.40 \\
\hline Met + Cys & 0.63 \\
\hline Thr & 0.85 \\
\hline $\operatorname{Trp}$ & 0.19 \\
\hline Val & 0.81 \\
\hline
\end{tabular}

Diets were fed $13 \mathrm{~d}$ prior to inoculation and $10 \mathrm{~d}$ after inoculation (23-d feeding study). Dietary addition of test articles (i.e., whole yeast cells and capsicum) did not replace other ingredients in the formulation (i.e., additives added on top of the control diet). SID = standardized ileal digestible.

${ }^{1}$ All values were obtained using swine NRC (2012), excluding the processed soy product where values were obtained from supplier.

${ }^{2}$ Dairylac 80; International Ingredients Corp., St. Louis, MO.

${ }^{3}$ Select menhaden; Omega Protein, Houston, TX.

${ }^{4} \mathrm{HP}$ 300; Hamlet Protein, Findlay, OH.

${ }^{5}$ Provided per kilogram of complete diet: vitamin A, 6600 IU; vitamin $\mathrm{D} 3,700 \mathrm{IU}$; vitamin $\mathrm{E}, 70 \mathrm{IU}$; vitamin $\mathrm{K}, 4 \mathrm{mg}$; vitamin B2, $4 \mathrm{mg}$; vitamin B3, $50 \mathrm{mg}$; vitamin B5, $24 \mathrm{mg}$; vitamin B6, $10 \mathrm{mg}$; vitamin B7, $0.2 \mathrm{mg}$; vitamin $\mathrm{B} 9,5 \mathrm{mg}$; and vitamin B12, $0.04 \mathrm{mg}$.

${ }^{6}$ Provided per kilogram of complete diet: $100 \mathrm{mg} \mathrm{Zn}$ from $\mathrm{ZnSO}_{4}$; $100 \mathrm{mg} \mathrm{Fe}$ from $\mathrm{FeSO}_{4} ; 10 \mathrm{mg} \mathrm{Mn}$ from $\mathrm{MnSO}_{4} ; 6 \mathrm{mg} \mathrm{Cu}$ from $\mathrm{CuSO}_{4}$; $0.3 \mathrm{mg}$ I from $\mathrm{Ca}\left(\mathrm{IO}_{3}\right)_{2}$; and $0.3 \mathrm{mg} \mathrm{Se}$ from $\mathrm{Na}_{2} \mathrm{SeO}_{3}$.

$3 \mathrm{~mL}$ dose) in PBS daily for 3 consecutive days, and the sham group was orally inoculated with a 3-mL dose of PBS as described for the challenged pigs. In aligning diets and experimental treatment groups, the unsupplemented control diet was fed to pigs assigned to both treatments 1 (sham-inoculated) and 2 (ETEC-inoculated), whereas ETECinoculated pigs assigned to treatments 3,4 , and 5 received diets 2,3 , and 4 , respectively.
Actual E. coli concentrations used in this study were $1.23 \times 10^{10}, 1.03 \times 10^{10}$, and $1.07 \times 10^{10}$ CFU for cohort 1 , and $9.75 \times 10^{11}, 2.13 \times 10^{11}$, and $3.42 \times 10^{11} \mathrm{CFU}$ for cohort 2 on consecutive inoculation days $(0,1$, and $2 \mathrm{~d}$ postinoculation [DPI], respectively). There were never detectable levels of ETEC quantified in the control (sham-inoculated) group throughout the study, proving that biosecurity measures were effective in preventing contamination, yet all challenged pigs were confirmed positive for the inoculation strain of ETEC administered.

\section{Growth Performance and Frequency of Diarrhea Analyses}

Pigs and feeders were weighed at weaning ( -13 DPI), the day of the first inoculation (0 DPI), and every $5 \mathrm{~d}$ thereafter (i.e., 5 and $10 \mathrm{DPI}$ ). Growth performance was calculated during the preinoculation period ( -13 to $0 \mathrm{DPI})$, and in 2 postinoculation periods (0 to 5 DPI [acute phase], and 5 to $10 \mathrm{DPI}$ [recovery phase]). Beginning at study initiation, pigs were observed twice daily and subjectively scored for the incidence of diarrhea as previously outlined by Ivers and Veum (2012). Daily observations were conducted by 2 individuals independently, and observers were blinded to dietary treatment. Fecal consistency was recorded as normal (no diarrhea) or diarrhea (i.e., watery feces compared with the normal feces). The incidence of diarrhea was reported as the number of experimental days of diarrhea per pig as a proportion of total study days within a given period (i.e., frequency of diarrhea).

\section{Blood Clinical Outcomes}

Blood samples were collected from the jugular vein of each pig on 7 DPI for submission to the Veterinary Clinical Pathology Laboratory at the University of Illinois at Urbana-Champaign for measuring total and differential blood cell counts. Blood was collected into 3-mL evacuated tubes containing no anticoagulant with a 21 -gauge needle that was $31.75 \mathrm{~mm}$ in length.

\section{Immunophenotyping}

Blood samples were collected from the jugular vein of each pig on 0 and 7 DPI. Blood was collected into a 4-mL evacuated tube containing $5.4 \mathrm{mg}$ of EDTA and placed on ice for $45 \mathrm{~min}$ until cell isolation was conducted using the Sepmate procedure (Stemcell Technologies, Vancouver, Canada). Briefly, blood was diluted with an equal 
volume of PBS containing 2\% fetal bovine serum (FBS) and pipetted into 15-mL Sepmate tubes containing $4.5 \mathrm{~mL}$ of density gradient medium. The Sepmate tubes were then centrifuged at $1,160 \times g$ for $10 \mathrm{~min}$. The top layer, containing peripheral blood mononuclear cells (PBMC), was then poured into a $15-\mathrm{mL}$ conical tube, washed, and then cells were counted using the Moxi 2 mini automated cell counter (ORFLO, Ketchum, ID) and the concentration was adjusted to $1 \times 10^{6}$ cells $/ \mathrm{mL}$ using high glucose Dulbecco's-modified eagle media (DMEM) supplemented with HEPES, sodium pyruvate, nonessential amino acids, sodium bicarbonate, and penicillin-streptomycin (ThermoFisher Scientific, Waltham, MA).

Cells were subsequently stained for surface CD (cluster of differentiation) markers for total, and different subsets of $\mathrm{T}$ cells, including CD3 (total $\mathrm{T}$ cell), CD4 ( $\mathrm{T}$ helper), and CD8 ( $\mathrm{T}$ cytotoxic) cells using porcine monoclonal antibodies specific for these $\mathrm{CD}$ markers and conjugated to a distinct fluorochrome (BD Biosciences, San Jose, CA). Once stained with these surface markers, the cells were washed and permanently fixed following manufacturer's instructions using the Cytofix/Cytoperm with Golgi stop kit (BD Biosciences, San Jose, CA). Finally the fixed cells were permeabilized and stained for the intracellular cytokine IFN- $\gamma$ using a porcine monoclonal antibody against IFN- $\gamma$ conjugated to a distinct fluorochrome (BD Biosciences, San Jose, CA). The relative percentage of different phenotypes of $\mathrm{T}$ cells (i.e., single positive $\mathrm{CD}^{+}$, $\mathrm{CD}^{+}$or double positive $\left[\mathrm{CD}^{+} \mathrm{CD}^{+}\right]$T-cells secreting IFN- $\gamma$ ) were determined using multicolor flow cytometry (BD LSR II flow cytometer; BD Biosciences, San Jose, CA) at the University of Illinois W. M. Keck Biotechnology Center.

\section{Fecal Bacterial Counts}

Fecal samples were collected from the rectum of each pig on 0,5 , and 10 DPI using a $22.86-\mathrm{cm}$ plastic fecal loop with a slotted end (Lambert Vet
Supply, NE). The samples were placed into a sterile 1.5-mL microcentrifuge tube and snap frozen in liquid nitrogen before being analyzed for total bacteria, total E. coli, and F18-fimbriated E. coli using validated quantitative real-time PCR (qRTPCR) procedures as follows. Total nucleic acid was extracted from 100 to $120 \mathrm{mg}$ of fecal material using a Biosprint 96 Work Station (Qiagen, Hayward, CA). Fecal samples were resuspended in $500 \mu \mathrm{L}$ of RNEasy lysis buffer and vortexed for $15 \mathrm{~s}$ to produce homogeneous mixtures. Then, $100 \mu \mathrm{L}$ of this mixture was processed according to manufacturer's recommendations using the One-For-AllVet Kit (Qiagen, Hayward, CA), and nucleic acids were eluted in $75 \mu \mathrm{L}$ of elution buffer. Quantitative real-time PCR was performed on an Eppendorf Mastercycler ep Realplex System (Eppendorf North America, Westbury Road, NY). The reaction mixture contained 1X Quanta PerfeCTa SYBR Green Supermix (Quanta Biosciences, Gaithersberg, MD 2087); $0.3 \mu \mathrm{M}$ each of the forward and reverse primers ( $g a d A B$ and $r r s)$ or $0.625 \mu \mathrm{M}$ of primers for $f e d A$, and $1 \mu \mathrm{L}$ of DNA in a total volume of $20 \mu \mathrm{L}$. The challenge $E$. coli strain used for inoculating pigs in the infected groups served as a positive control.

The following thermal cycling profile was used for all amplifications: an initial denaturation at $95^{\circ} \mathrm{C}$ for $180 \mathrm{~s}$, plus 45 repeating cycles with samples at $95{ }^{\circ} \mathrm{C}$ for $15 \mathrm{~s}, 60^{\circ} \mathrm{C}$ for $30 \mathrm{~s}$, and $72{ }^{\circ} \mathrm{C}$ for $30 \mathrm{~s}$. Finally, a postamplification thermal dissociation curve analysis of the amplification products was conducted using a thermal gradient of $60{ }^{\circ} \mathrm{C}$ to $90{ }^{\circ} \mathrm{C}$ in increments of $0.2{ }^{\circ} \mathrm{C} / \mathrm{s}$ to further facilitate data collection. All primers were synthesized by Integrated DNA Technologies (IDT, Coralville, IA) as described in Table 2.

\section{Recall Nitric Oxide Analysis}

For recall nitric oxide (NO) analysis, blood was collected on 10 DPI immediately after euthanasia via the carotid artery, placed into $50-\mathrm{mL}$ conical tubes containing 5\% EDTA, and set on ice for

Table 2. Analytical details regarding quantification of bacterial gene expression

\begin{tabular}{|c|c|c|c|c|}
\hline Target & Gene & Primer sequences $^{1}$ & Amplicon & Reference \\
\hline \multirow[t]{2}{*}{$\overline{\mathrm{F} 18^{+} \text {E. coli }}$} & fedA & 5'-GTGAAAAGACTAGTGTTTATTTC-3' & $510 \mathrm{bp}$ & DebRoy and Maddox, 2001 \\
\hline & & 5'-CTTGTAAGTAACCGCGTAAGC-3' & & \\
\hline \multirow[t]{2}{*}{ Total E. coli } & $\operatorname{gad} A B$ & 5'-GCGTTGCGTAAATATGGTTGCCGA-3' & $305 \mathrm{bp}$ & Chen et al., 2006 \\
\hline & & 5'-CGTCACAGGCTTCAATCATGCGTT-3' & & \\
\hline \multirow[t]{2}{*}{ Total bacteria } & $r r s$ & 5'-GGATTAGATACCCTGGTAGTCC-3' & $320 \mathrm{bp}$ & Kariyama et al., 2000 \\
\hline & & 5'-TCGTTGCGGGACTTAACCCAAC-3' & & \\
\hline
\end{tabular}

${ }^{1}$ Forward and reverse sequences are shown on the top and bottom line, respectively, for each gene. 
$1 \mathrm{~h}$ pending PBMC isolation procedures using the Sepmate procedure described above. At the final step, isolated cells were counted using the Moxi 2 mini automated cell counter (ORFLO, Ketchum, ID) and the concentration was adjusted to $2 \times$ $10^{6}$ cells $/ \mathrm{mL}$ using DMEM as described above (ThermoFisher Scientific, Waltham, MA). Cells were plated in triplicate in 24-well cell culture plates in DMEM (ThermoFisher Scientific, Waltham, MA) and allowed to grow and adhere for $24 \mathrm{~h}$. Due to complications with adherence of cells isolated from pigs enrolled in the first cohort, NO data were only collected from pigs in the second cohort. After the 24-h growth period, adherent cells considered to be of monocyte and/or dendritic cell lineage were retained, and the nonadherent cells were discarded along with the media from each well. The adhered monocytes were then stimulated with $50 \mu \mathrm{g} / \mathrm{mL}$ of E. coli 0111:B4 lipopolysaccharide (Sigma-Aldrich, St. Louis, MO) in the appropriate medium for 24 or $48 \mathrm{~h}$. At the appropriate endpoint, supernatant from each well was pooled into two $1.5-\mathrm{mL}$ microcentrifuge tubes and stored at $4{ }^{\circ} \mathrm{C}$ pending $\mathrm{NO}$ quantification.

Samples were analyzed using a nitrate/nitrite colorimetric assay kit (Caymen Chemical, Ann Arbor, MI). Briefly, the kit follows a 2-step process, with the first step being the conversion of nitrate to nitrite utilizing nitrate reductase. The second step uses Griess reagent which converts nitrite into a purple azo compound. The photometric measurement of absorbance of the azo compound is what accurately determines nitrite concentration in an indirect fashion. Samples were diluted 2:1 with an assay buffer, plated in a 96-well plate in triplicate in a total volume of $80 \mu \mathrm{L}$, and the nitrate reductase enzyme cofactor and enzyme mixture were added to each well. The plate was allowed to incubate at room temperature for $2 \mathrm{~h}$ and then Griess reagents R1 and R2 were added to each well per manufacturer's instructions. The color was allowed to develop for $10 \mathrm{~min}$ at room temperature, and then the plate was read using a Synergy HT micro-plate reader at $540 \mathrm{~nm}$ (BioTek, Winooski, VT).

\section{Statistical Analyses}

All data involving infected groups were analyzed as a 2-way ANOVA (SAS Institute Inc., Cary, NC), with a separate comparison (independent, pairwise comparison by $t$-test) between unchallenged and challenged control-fed pigs. Because frequency of diarrhea was recorded as a binomial variable, these data were analyzed using a chi-square test.
Individual pig served as the experimental unit for all outcomes, and significance among means was assessed using an alpha level of 0.05 , with trends being recognized when the alpha level was between 0.05 and 0.10 .

\section{RESULTS}

\section{Growth Performance and Diarrhea Frequency}

All ETEC-challenged pigs showed signs of infection, including increased incidence of diarrhea, but appeared to recover from the induction of mild-to-moderate diarrhea by study conclusion. All of the sham-inoculated animals remained free of ETEC and met expectations for growth performance in the biocontainment facility (Table 3). Although there were no interactive effects observed for growth performance outcomes, main effects revealed that WYC increased $(P<0.05)$, and capsicum decreased $(P<0.05)$, ADFI from 0 to 10 DPI. Additionally, main effects of WYC were evident for feed efficiency (i.e., gain:feed) from 0 to 5 DPI, 5 to $10 \mathrm{DPI}$, and 0 to $10 \mathrm{DPI}(P<0.05)$, though this effect was largely driven by the response of pigs assigned to treatment 4.

None of the sham-inoculated (i.e., uninfected) pigs exhibited diarrhea postinoculation, so a comparison between the negative and positive control pigs was not made for this outcome. Pigs challenged with ETEC and fed diets containing WYC or capsicum alone had a higher frequency of diarrhea when compared with pigs receiving diets without those compounds (main effect of WYC, $P=0.01$; main effect of essential oil, $P=0.02$ ). This effect was largely driven by ETEC-challenged pigs fed the control diet having the lowest diarrhea frequency and those receiving the combination diet having the highest diarrhea frequency.

\section{Fecal Bacterial Counts}

On 5 DPI, there were detectable levels of the F18 E. coli strain in challenged pigs only, confirming there was no cross-contamination of the chosen $E$. coli strain with the sham-inoculated pigs (Table 4). Total fecal bacterial counts were highest $(P=0.05)$ in pigs fed the combination diet at 5 DPI when compared with all other infected groups. Total fecal bacteria were highest $(P=0.02)$ in pigs fed the capsicum diet at 5 DPI when compared with those fed the diet containing WYC alone. The WYC product, either alone or in combination with capsicum, had no significant effect on total bacteria 
Table 3. Effects of whole yeast cells and capsicum on growth performance and diarrhea incidence in weanling pigs challenged with a pathogenic $E$. coli

\begin{tabular}{|c|c|c|c|c|c|c|c|c|c|c|}
\hline \multirow[b]{2}{*}{ Treatment } & \multirow{2}{*}{$\begin{array}{c}\text { Sham } \\
1\end{array}$} & \multicolumn{4}{|c|}{ F18 $8^{+}$E. coli-inoculated } & \multirow[b]{3}{*}{ Pooled } & & & & \\
\hline & & 2 & 3 & 4 & 5 & & \multicolumn{4}{|c|}{$P$-value } \\
\hline \multirow[b]{2}{*}{ WYC Capsicum } & \multirow{2}{*}{$\frac{-}{-}$} & \multirow{2}{*}{-} & + & - & + & & \multirow[b]{2}{*}{ Challenge $^{1}$} & \multicolumn{3}{|c|}{$\begin{array}{c}\text { Within F18 } \\
\text { E. coli-inoculated groups }\end{array}$} \\
\hline & & & - & + & + & SEM & & WYC & Capsicum & Interaction \\
\hline \multicolumn{11}{|l|}{ Preinoculation } \\
\hline Initial BW, $\mathrm{kg}$ & 6.02 & 6.15 & 6.16 & 6.13 & 6.13 & 0.31 & 0.35 & 0.97 & 0.84 & 0.97 \\
\hline ADG, $g$ & 243 & 240 & 214 & 231 & 248 & 30.45 & 0.91 & 0.81 & 0.50 & 0.24 \\
\hline ADFI, $g$ & 787 & 808 & 1040 & 646 & 819 & 138.6 & 0.91 & 0.13 & 0.15 & 0.82 \\
\hline $\mathrm{G}: \mathrm{F}, \mathrm{g} / \mathrm{kg}$ & 328 & 364 & 298 & 449 & 412 & 56.91 & 0.65 & 0.33 & 0.07 & 0.79 \\
\hline Diarrhea frequency, $\%{ }^{2}$ & 2.30 & 1.78 & 2.37 & 1.48 & 0.60 & - & 0.74 & 0.70 & 0.23 & 0.18 \\
\hline \multicolumn{11}{|l|}{ Postinoculation } \\
\hline Initial BW, kg & 9.24 & 9.27 & 8.94 & 9.14 & 9.31 & 0.65 & 0.92 & 0.75 & 0.65 & 0.31 \\
\hline \multicolumn{11}{|l|}{ ADG, $\mathrm{g}$} \\
\hline 0-5 DPI & 485 & 435 & 371 & 408 & 248 & 63.80 & 0.56 & 0.05 & 0.19 & 0.40 \\
\hline 5-10 DPI & 675 & 602 & 622 & 626 & 539 & 53.36 & 0.20 & 0.39 & 0.45 & 0.17 \\
\hline 0-10 DPI & 583 & 535 & 503 & 516 & 389 & 45.91 & 0.44 & 0.07 & 0.13 & 0.27 \\
\hline \multicolumn{11}{|l|}{ ADFI, g } \\
\hline 0-5 DPI & 1258 & 1289 & 1629 & 893 & 1506 & 296.2 & 0.91 & 0.01 & 0.17 & 0.47 \\
\hline 5-10 DPI & 1374 & 1488 & 1645 & 982 & 1170 & 216.9 & 0.65 & 0.32 & 0.01 & 0.93 \\
\hline 0-10 DPI & 1308 & 1282 & 1637 & 896 & 1288 & 226.6 & 0.91 & 0.02 & 0.03 & 0.91 \\
\hline \multicolumn{11}{|l|}{$\mathrm{G}: \mathrm{F}, \mathrm{g} / \mathrm{kg}$} \\
\hline 0-5 DPI & 445 & 378 & 290 & 475 & 262 & 96.37 & 0.48 & 0.02 & 0.59 & 0.34 \\
\hline 5-10 DPI & 560 & 457 & 423 & 718 & 490 & 64.85 & 0.25 & 0.04 & 0.01 & 0.12 \\
\hline 0-10 DPI & 500 & 415 & 322 & 582 & 345 & 68.07 & 0.27 & 0.003 & 0.08 & 0.18 \\
\hline Final BW, kg & 15.04 & 14.58 & 14.04 & 14.18 & 13.21 & 0.82 & 0.57 & 0.19 & 0.30 & 0.70 \\
\hline Diarrhea frequency, $\% 0^{2}$ & 0.00 & 17.09 & 18.36 & 17.77 & 21.17 & - & $<0.01$ & 0.01 & 0.02 & 0.59 \\
\hline
\end{tabular}

Values represent least squares means of 12 replicates for the unchallenged control animals and 13 replicates per challenged treatment. Pigs were inoculated on 0 , 1, and 2 DPI with either a 3-mL dose of PBS (sham) or F18 $8^{+}$. coli (challenged). Treatment annotations: "-_" indicates that the diet did not contain the test article, whereas "+" indicates that the test article was provided via the diet. The lack of either test article being provided indicates the control diet (i.e., treatments 1 and 2). DPI = days postinoculation; WYC $=$ whole yeast cells.

${ }^{2} P$ value for the pairwise comparison of treatments 1 and 2 (i.e., sham vs. challenged pigs fed the control diet).

${ }^{3}$ Defined as (diarrhea-days/by pig-days) $\times 100 \%$, where pig-days is the total number of pigs per treatment multiplied by the number of days of diarrhea scoring per period, and diarrhea-days is the total number of pig-days that were scored as pigs experiencing diarrhea. Diarrhea frequency was recorded as a binomial variable such that the data were analyzed using a chi-square test.

counts at 0,5 , or $10 \mathrm{DPI}$. At $10 \mathrm{DPI}$, pigs fed the combination diet had the lowest $(P=0.03)$ total bacteria counts when compared with either additive alone, but trended toward having the highest $(P=0.07)$ total fecal E. coli counts at $10 \mathrm{DPI}$.

\section{Clinical Blood Outcomes}

Dietary treatment effects were observed for differential leukocyte counts in infected pigs on 7 DPI (Table 5). Blood leukocyte counts were increased in infected pigs receiving the combination of WYC and capsicum compared with all other infected groups (interaction, $P=0.04$ ). Pigs fed WYC exhibited increased lymphocyte counts (main effect, $P=0.02$ ); however, pigs fed the combination of additives also tended to exhibit increased lymphocyte counts (interaction, $P=0.09$ ). Similar neutrophil levels were observed across all the infected groups.

\section{T-Cell Immunophenotyping}

Pigs fed the combination of additives had significantly lower percentages of $\mathrm{CD}^{+}(P=0.05)$ and $\mathrm{CD}^{+} \mathrm{CD}^{+}(P=0.02)$ T-cells when compared with pigs fed either additive alone on 0 DPI (Table 6). Pigs fed the combination of additives also had lower percentages of $\mathrm{CD}^{+}(P=0.02)$ and $\mathrm{CD} 4^{+} \mathrm{CD} 8^{+}$ $(P=0.02)$ cells on $7 \mathrm{DPI}$, showing that there were less cytotoxic T-cells $\left(\mathrm{CD}^{+}\right)$and less effector memory T-cells $\left(\mathrm{CD}^{+} \mathrm{CD}^{+}\right)$present in the blood after inoculation when compared with either additive alone. The WYC product alone tended to increase 
Table 4. Effects of whole yeast cells and capsicum on fecal bacterial profiles [cycle threshold (Ct) values] and in weanling pigs challenged with a pathogenic $E$. coli

\begin{tabular}{|c|c|c|c|c|c|c|c|c|c|c|}
\hline \multirow[b]{2}{*}{ Treatment } & \multirow{2}{*}{$\frac{\text { Sham }}{1}$} & \multicolumn{4}{|c|}{ F18 $8^{+}$E. coli-inoculated } & \multirow[b]{4}{*}{ Pooled SEM } & & & & \\
\hline & & \multirow[t]{2}{*}{2} & 3 & 4 & 5 & & \multicolumn{4}{|c|}{$P$-value } \\
\hline & - & & + & - & + & & \multirow[b]{2}{*}{ Challenge $^{1}$} & \multicolumn{3}{|c|}{$\begin{array}{c}\text { Within F18 } \\
\text { E. coli-inoculated groups }\end{array}$} \\
\hline WYC Capsicum & - & - & - & + & + & & & WYC & Capsicum & Interaction \\
\hline \multicolumn{11}{|l|}{$\overline{0 \mathrm{DPI}}$} \\
\hline$n$ & 11 & 13 & 13 & 13 & 11 & & & & & \\
\hline F18 $8^{+}$E. coli & ND & ND & ND & ND & ND & - & - & - & - & - \\
\hline Total E. coli & 26.80 & 26.96 & 25.73 & 26.58 & 27.06 & 0.992 & 0.91 & 0.69 & 0.61 & 0.36 \\
\hline Total bacteria & 15.05 & 12.87 & 13.47 & 13.97 & 13.27 & 0.843 & 0.06 & 0.96 & 0.57 & 0.42 \\
\hline \multicolumn{11}{|l|}{$5 \mathrm{DPI}$} \\
\hline$n$ & 11 & 11 & 12 & 11 & 10 & & & & & \\
\hline $\mathrm{F} 18^{+}$E. coli & ND & 22.71 & 24.82 & 29.49 & 27.40 & 5.65 & - & 0.99 & 0.19 & 0.55 \\
\hline Total E. coli & 27.19 & 22.99 & 22.30 & 21.47 & 18.94 & 1.78 & 0.04 & 0.26 & 0.09 & 0.51 \\
\hline Total bacteria & 14.54 & $14.29^{\mathrm{b}}$ & $14.44^{\mathrm{b}}$ & $14.11^{\mathrm{b}}$ & $12.90^{\mathrm{a}}$ & 0.655 & 0.60 & 0.13 & 0.02 & 0.05 \\
\hline \multicolumn{11}{|l|}{10 DPI } \\
\hline$n$ & 11 & 9 & 12 & 12 & 9 & & & & & \\
\hline $\mathrm{F} 18^{+}$E. coli & ND & ND & ND & ND & ND & - & - & - & - & - \\
\hline Total E. coli & 28.25 & 26.78 & 29.99 & 29.61 & 28.78 & 1.16 & 0.35 & 0.28 & 0.46 & 0.07 \\
\hline Total bacteria & 13.95 & $14.31^{\mathrm{b}}$ & $13.78^{\mathrm{ab}}$ & $13.55^{\mathrm{a}}$ & $14.09^{\mathrm{ab}}$ & 0.460 & 0.29 & 0.99 & 0.36 & 0.03 \\
\hline
\end{tabular}

${ }^{a b}$ Means lacking a common superscript letter differ $(P<0.05)$

Values represent least squares means of 12 replicates for the unchallenged control animals and 13 replicates per challenged treatment. Pigs were inoculated on 0,1 , and 2 DPI with either a 3-mL dose of PBS (sham) or F18 $E$. coli (challenged). Treatment annotations: "-" indicates that the diet did not contain the test article, whereas " + " indicates that the test article was provided via the diet. The lack of either test article being provided indicates the control diet (i.e., treatments 1 and 2). DPI $=$ days postinoculation; ND $=$ nondetectable levels; WYC $=$ whole yeast cells.

${ }^{1} P$ value for the pairwise comparison of treatments 1 and 2 (i.e., sham vs. challenged pigs fed the control diet).

the proportion of $\mathrm{CD}^{+}$cells on 7 DPI $(P=0.09)$. No differences were observed for the proportion of effector memory T-cells that secrete IFN- $\gamma$ between infected groups.

\section{Nitric Oxide Production}

Cells isolated from pigs fed capsicum alone exhibited lower NO production upon stimulation with LPS when compared with PBMC from pigs fed WYC alone at $24 \mathrm{~h}$ (Figure 1). Pigs fed the capsicum-only diet had less NO production at $24 \mathrm{~h}$ in LPS-stimulated cells $(P=0.02)$ compared with cells from pigs fed the diet containing WYC alone. There were no differences in NO production from PBMC isolated from pigs in the infected groups after $48 \mathrm{~h}$ of culture, though NO values for PBMC cells derived from pigs on each dietary treatment were numerically lower when compared with NO values recorded $24 \mathrm{~h}$ after LPS stimulation.

\section{DISCUSSION}

Based on previous research indicating that prebiotics and plant essential oils had beneficial effects on pigs challenged with E. coli (Yaqoob and Calder, 2011; Liu et al., 2012; Vieira et al., 2013), we hypothesized that WYC and capsicum, alone or in combination, would reduce colonization of ETEC and support a more effective immune response. In general, induction of an ETEC challenge elicited no changes in growth performance, blood clinical outcomes, or the reactivity of PBMC stimulated with LPS when comparing sham- and ETECinoculated groups, yet the incidence of diarrhea was influenced in this challenge model. Studies by Davis et al. (1999) and van der Peet-Schweing et al. (2007) both observed that yeast products served as an effective alternative to conventional antimicrobials in weanling pigs, whereas Sads and Bilkei (2003) reported plant extracts to improve growth performance of immune-challenged pigs. However, growth performance responses to yeast products and plant extracts appear to be highly variable. In our study, neither the WYC product nor capsicum affected growth performance of ETEC-challenged pigs (no overall detriments to growth performance were observed due to ETEC infection), opposite to what we hypothesized, but similar to results reported by Kornegay et al. (1995), LeMieux et al. (2003), and Liu et al. (2013). Lack of increases in growth performance may be due to the levels of additives being too low to elicit large enhancements 
Table 5. Effects of whole yeast cells and capsicum on differential leukocyte counts on 7 DPI in weanling pigs challenged with a pathogenic $E$. coli

\begin{tabular}{|c|c|c|c|c|c|c|c|c|c|c|}
\hline \multirow[b]{2}{*}{ Treatment } & \multirow{2}{*}{$\frac{\text { Sham }}{1}$} & \multicolumn{4}{|c|}{ F18 $8^{+}$E. coli-inoculated } & \multirow[b]{4}{*}{ Pooled SEM } & & & & \\
\hline & & 2 & 3 & 4 & 5 & & \multicolumn{4}{|c|}{$P$-value } \\
\hline \multirow[b]{2}{*}{ WYC Capsicum } & \multirow{2}{*}{-} & \multirow{2}{*}{-} & \multirow{2}{*}{+} & \multirow{2}{*}{-} & + & & \multirow[b]{2}{*}{ Challenge $^{1}$} & \multicolumn{3}{|c|}{$\begin{array}{c}\text { Within } \mathrm{F} 18^{+} \\
\text {E. coli-inoculated groups }\end{array}$} \\
\hline & & & & & + & & & WYC & Capsicum & Interaction \\
\hline \multicolumn{11}{|c|}{ Absolute count, $10^{3} / \mu \mathrm{L}$} \\
\hline Platelets & 622.7 & 664.0 & 582.6 & 553.2 & 584.1 & 89.3 & 0.56 & 0.62 & 0.28 & 0.27 \\
\hline WBC & 19.80 & $23.24^{\mathrm{ab}}$ & $24.01^{\mathrm{ab}}$ & $18.92^{\mathrm{a}}$ & $27.63^{\mathrm{b}}$ & 3.14 & 0.21 & 0.01 & 0.86 & 0.04 \\
\hline NEU & 8.26 & 9.05 & 8.81 & 6.78 & 8.36 & 1.18 & 0.53 & 0.45 & 0.14 & 0.32 \\
\hline LYMPH & 10.07 & 12.21 & 13.36 & 10.80 & 17.44 & 2.52 & 0.34 & 0.02 & 0.40 & 0.09 \\
\hline NEU/LYMPH & 0.89 & 0.95 & 0.78 & 0.69 & 0.58 & 0.16 & 0.75 & 0.34 & 0.11 & 0.82 \\
\hline MONO & 1.10 & 1.51 & 1.35 & 0.92 & 1.28 & 0.31 & 0.23 & 0.68 & 0.18 & 0.28 \\
\hline EOS & 0.26 & 0.31 & 0.22 & 0.28 & 0.10 & 0.08 & 0.60 & 0.07 & 0.32 & 0.58 \\
\hline BASO & 0.11 & 0.12 & 0.17 & 0.10 & 0.10 & 0.07 & 0.88 & 0.73 & 0.43 & 0.65 \\
\hline \multicolumn{11}{|c|}{ Relative proportion, $\%{ }^{2}$} \\
\hline $\mathrm{NEU}$ & 41.8 & 40.9 & 37.2 & 35.8 & 32.3 & 4.04 & 0.85 & 0.32 & 0.17 & 0.99 \\
\hline LYMPH & 50.6 & 50.4 & 55.0 & 56.8 & 61.3 & 3.79 & 0.97 & 0.20 & 0.08 & 0.99 \\
\hline MONO & 5.6 & 6.3 & 5.8 & 5.0 & 4.8 & 1.58 & 0.55 & 0.70 & 0.18 & 0.85 \\
\hline EOS & 1.2 & 1.4 & 1.0 & 1.6 & 0.4 & 0.35 & 0.74 & 0.01 & 0.63 & 0.21 \\
\hline BASO & 0.5 & 0.6 & 0.6 & 0.6 & 0.4 & 0.27 & 0.74 & 0.66 & 0.57 & 0.79 \\
\hline
\end{tabular}

${ }^{a b}$ Means lacking a common superscript letter differ $(P<0.05)$.

Values represent least squares means of 12 replicates for the unchallenged control animals and 13 replicates per challenged treatment. Pigs were inoculated on 0,1 , and 2 DPI with either a 3 -mL dose of PBS (sham) or F18+ E. coli (challenged). Treatment annotations: "-” indicates that the diet did not contain the test article, whereas "+" indicates that the test article was provided via the diet. The lack of either test article being provided indicates the control diet (i.e., treatments 1 and 2). BASO = basophils; DPI $=$ days postinoculation; $\mathrm{EOS}=$ eosinophils; $\mathrm{LYMPH}=$ lymphocytes; $\mathrm{MONO}=$ monocytes; $\mathrm{NEU}=$ neutrophils; $\mathrm{WBC}=$ white blood cells; $\mathrm{WYC}=$ whole yeast cells.

${ }^{1} P$ value for the pairwise comparison of treatments 1 and 2 (i.e., sham vs. challenged pigs fed the control diet).

${ }^{2}$ Differential cell counts expressed relative to absolute WBC count.

in growth, as White et al. (2002) included dried yeast at 3\% and reported no increases in growth performance, whereas the levels used in our study were much lower at $0.2 \%$.

Although previous studies have shown that capsicum may reduce the incidence of diarrhea in E. coli-challenged pigs (Liu et al., 2013), data from our study suggested a higher frequency of diarrhea in challenged pigs fed either WYC or capsicum alone. Surprisingly, a combination of the 2 additives yielded the highest incidence of diarrhea overall, which is certainly counter to our hypothesis. Although the frequency of diarrhea in these challenged pigs was numerically higher, it did not appear to adversely affect growth performance of the ETEC-challenged pigs. The lack of effect on growth performance may indicate that the ETEC infection was not severe enough to affect growth performance while still causing diarrhea.

Because ingredients with potential to serve as prebiotic substrates have been shown to compete for ETEC binding sites, thereby allowing more ETEC to be shed in the feces instead of binding to the intestinal epithelium (Baumler et al., 1997; Kogan and Kocher, 2007), we quantified fecal bacterial counts. No significant differences were observed between treatments for excretion of $\mathrm{F}^{+} 8^{+}$E. coli; however, challenged pigs fed the combination of additives tended to have higher fecal shedding of total bacteria than pigs fed either additive alone at 5 DPI. Although no significant effect was observed in pigs fed WYC alone, the effectiveness of the feed additive combination to increase total fecal bacteria may have implications for either gut health or food safety. The increased shedding of total bacteria at 5 DPI from pigs fed the combination diet may be due to combined effects of the mannan fraction of the WYC product to competitively bind pathogenic ETEC and prevent colonization (Firon et al., 1983; Baumler et al., 1997; Kogan and Kocher, 2007) and the potential for capsicum to directly kill pathogenic bacteria (Hammer et al., 1999). At 10 DPI, pigs fed the additive combination had lower total fecal bacterial shedding, but tended to exhibit higher $E$. coli shedding compared with all other infected groups. This rapid, 5-d reduction in fecal ETEC shedding may indicate a return to intestinal homeostasis, with bacterial shedding decreasing as 
Table 6. Effects of whole yeast cells and capsicum on T-cell proportions ( $\%$ of total isolated CD $3^{+} \mathrm{T}$-cells) in weanling pigs challenged with a pathogenic E. coli

\begin{tabular}{|c|c|c|c|c|c|c|c|c|c|c|}
\hline \multirow[b]{2}{*}{ Treatment } & \multirow{2}{*}{$\frac{\text { Sham }}{1}$} & \multicolumn{4}{|c|}{$\mathrm{F} 18^{+}$E. coli-inoculated } & \multirow[b]{4}{*}{ Pooled SEM } & & & & \\
\hline & & 2 & 3 & 4 & 5 & & \multicolumn{4}{|c|}{$P$-value } \\
\hline \multirow[b]{2}{*}{ WYC Capsicum } & \multirow{2}{*}{$\frac{-}{-}$} & \multirow{2}{*}{-} & \multirow{2}{*}{+} & \multirow{2}{*}{$\frac{-}{+}$} & \multirow{2}{*}{$\frac{+}{+}$} & & \multirow[b]{2}{*}{ Challenge $^{1}$} & \multicolumn{3}{|c|}{$\begin{array}{c}\text { Within } \mathrm{F} 18^{+} \\
\text {E. coli-inoculated groups }\end{array}$} \\
\hline & & & & & & & & WYC & Capsicum & Interaction \\
\hline \multicolumn{11}{|l|}{$0 \mathrm{DPI}$} \\
\hline$n$ & 11 & 13 & 13 & 12 & 12 & & & & & \\
\hline $\mathrm{CD}^{-}{ }^{-} \mathrm{CD} 8^{-}$cells & 54.5 & 54.0 & 54.9 & 48.6 & 56.0 & 5.05 & 0.90 & 0.16 & 0.47 & 0.28 \\
\hline $\mathrm{CD}^{+}{ }^{+}$cells & 24.7 & 23.0 & 20.1 & 22.4 & 23.9 & 1.98 & 0.52 & 0.70 & 0.38 & 0.24 \\
\hline $\mathrm{CD}^{+}$cells & 17.8 & $19.9^{\mathrm{ab}}$ & $21.2^{\mathrm{ab}}$ & $23.6^{\mathrm{b}}$ & $16.9^{\mathrm{a}}$ & 4.99 & 0.49 & 0.19 & 0.89 & 0.05 \\
\hline $\mathrm{CD}^{+}{ }^{+} \mathrm{CD} 8^{+}$cells & 3.1 & $3.1^{\mathrm{a}}$ & $3.7^{\mathrm{ab}}$ & $5.3^{\mathrm{b}}$ & $3.1^{\mathrm{a}}$ & 0.83 & 0.99 & 0.18 & 0.20 & 0.02 \\
\hline IFN- $\gamma^{+}$cells & 63.0 & 61.0 & 64.2 & 60.3 & 67.2 & 10.6 & 0.77 & 0.27 & 0.80 & 0.69 \\
\hline \multicolumn{11}{|l|}{7 DPI } \\
\hline$n$ & 10 & 11 & 13 & 12 & 10 & & & & & \\
\hline $\mathrm{CD}^{-} \mathrm{CD}^{-}$cells & 57.8 & 59.3 & 57.5 & 56.6 & 61.8 & 3.97 & 0.63 & 0.42 & 0.71 & 0.10 \\
\hline $\mathrm{CD}^{+}$cells & 23.0 & 23.1 & 20.4 & 21.8 & 19.4 & 3.81 & 0.95 & 0.09 & 0.46 & 0.92 \\
\hline $\mathrm{CD}^{+}$cells & 15.9 & $14.4^{\mathrm{a}}$ & $17.8^{\mathrm{b}}$ & $17.0^{\mathrm{ab}}$ & $15.0^{\mathrm{ab}}$ & 1.30 & 0.37 & 0.53 & 0.96 & 0.02 \\
\hline $\mathrm{CD}^{+} \mathrm{CD}^{+}$cells & 3.2 & $3.2^{\mathrm{a}}$ & $4.4^{\mathrm{b}}$ & $4.7^{\mathrm{b}}$ & $3.8^{\mathrm{ab}}$ & 0.47 & 0.93 & 0.66 & 0.32 & 0.02 \\
\hline IFN- $\gamma^{+}$cells & 46.8 & 55.3 & 49.8 & 48.0 & 50.4 & 7.79 & 0.17 & 0.70 & 0.42 & 0.35 \\
\hline
\end{tabular}

${ }^{\text {ab }}$ Means lacking a common superscript letter differ $(P<0.05)$.

Values represent least squares means of 12 replicates for the unchallenged control animals and 13 replicates per challenged treatment. Pigs were inoculated on 0,1 , and 2 DPI with either a 3-mL dose of PBS (sham) or F18 $E$. coli (challenged). Treatment annotations: "-" indicates that the diet did not contain the test article, whereas "+" indicates that the test article was provided via the diet. The lack of either test article being provided indicates the control diet (i.e., treatments 1 and 2). DPI $=$ days postinoculation; $\mathrm{WYC}=$ whole yeast cells.

${ }^{1} P$ value for the pairwise comparison of treatments 1 and 2 (i.e., sham vs. challenged pigs fed the control diet).

the gut recovered from ETEC infection and relatively smaller populations of $E$. coli remaining in the colon.

Ingredients with proven prebiotic potential have been shown to reduce the inflammatory response and alleviate detrimental effects of ETEC, purportedly, in part, through the production of SCFA from microbial fermentation (Yaqoob and Calder, 2011; Vieira et al., 2013). Receptors for SCFA on immune cells, such as eosinophils and neutrophils, may help strengthen the immune response, contributing to the immunomodulatory effects of prebiotics (Maslowski et al., 2009; Kim et al., 2013). Although we postulated that the WYC product may serve as a prebiotic additive, we did not quantify SCFA profiles in the feces of pigs enrolled in our study, so we are unable to speculate on whether changes in fermentative profiles were related to study outcomes. Additional evidence is needed to elucidate whether benefits of SCFA production relate to the ability for pigs to mount an effective immune response to ETEC.

We also hypothesized that WYC and capsicum would enhance the immune response of pigs challenged with ETEC to lessen the severity of infection and allow pigs to restore homeostasis in a shorter period of time. Those pigs fed the combination diet had higher circulating lymphocyte counts, whereas neutrophil counts remained similar overall, meaning the neutrophil-to-lymphocyte ratio decreased; a clinical indication of reduced inflammation (Widowski et al., 1989). This fits with recent reports that both yeast products, like mannan oligosaccharides and beta-glucan, and plant essential oils may down-regulate the production of pro-inflammatory cytokines (Li et al., 2006; Che et al., 2008; Liu et al., 2012). Davis et al. (1999) also reported that pigs fed mannan oligosaccharides had lower neutrophil counts and higher lymphocytes counts, corroborating observations from our current study.

Data from our study indicated that neither additive alone affected T-cell subsets, and only when fed in combination did we observe a decrease in both cytotoxic and memory T-cells. Passive immunity that pigs acquire from the sow's milk are depleted by the time the pigs are weaned (King and Pluske, 2003; Gallois et al., 2009). This leaves the immune system of the weanling pig relatively under-developed at the time of weaning. When combined with weaning stressors, not limited to a novel environment and diet, the immune system can be overwhelmed with new antigens that cause intestinal inflammation and an increase in both $\mathrm{CD}^{+}$and $\mathrm{CD} 8^{+} \mathrm{T}$-cell populations shortly after weaning (McCracken 


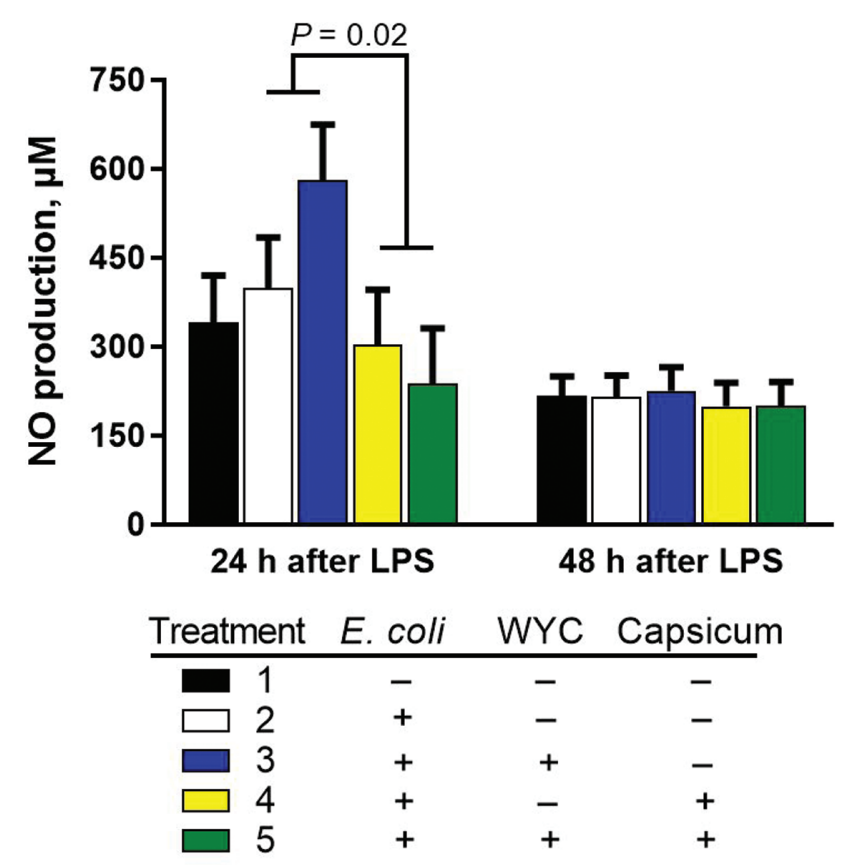

Figure 1. Effects of LPS on NO produced by porcine mononuclear cells isolated from weanling pigs $10 \mathrm{~d}$ after initial challenge with pathogenic E. coli. Values represent least squares means of 12 and 13 replicate pigs for the unchallenged control and challenged treatments, respectively. Pigs were inoculated with $E$. coli once per day for 3 consecutive days with either a 3-mL dose of PBS (unchallenged, receiving control diet only) or F-18+E. coli (challenged) and provided diets without or with WYC or capsicum in a $2 \times 2$ factorial arrangement. Subsequent to isolation procedures, peripheral blood mononuclear cells were treated with $1 \mathrm{~mL}$ of complete media containing $0.5 \mu \mathrm{g}$ of LPS and the cellular supernatant was collected for NO analysis at either 24 or $48 \mathrm{~h}$ after the time of LPS stimulation to perform the inflammatory recall assay. Although there were no differences between unchallenged and $E$. coli-challenged pigs receiving the control diet $(P>0.62)$, a main effect of capsicum was observed $(P=0.02)$, but neither the main effect of WYC $(P=0.53)$ nor the interactive effect $(P=0.19)$ was significant. LPS $=$ lipopolysaccharide $; \mathrm{NO}=$ nitric oxide $; \mathrm{WYC}=$ whole yeast cells.

et al., 1999; Moeser et al., 2007). The combination of capsicum and WYC decreased $\mathrm{CD} 8^{+}$cells before inoculation, meaning this additive combination may be a viable nutritional manipulation to counteract postweaning inflammation. The continued reduction in cytotoxic and helper T-cell subpopulations at 7 DPI in pigs fed the combination diet suggests that a lesser adaptive immune response may have been mounted against ETEC infection. This could be due to the innate response being more effective in these animals, in coordination with a reduced inflammatory response as indicated by observed lymphocyte counts, and may indicate that the combination of feed additives allowed pigs to be more effective at clearing ETEC infection (i.e., more efficient immune response) than when either additive was fed alone.

Nitric oxide production is necessary for a robust immune response as it has cytotoxic properties capable of damaging pathogenic microbes through oxidation of DNA, proteins, and lipids (Korhonen et al., 2005; Li et al., 2006). Li et al. (2006) and Lee et al. (2002) provided evidence that plant extracts can inhibit NO production due to plant extracts being a source of bioactive chemicals and chemotherapeutic reagents (Lee et al., 2000). We observed that PBMC isolated from pigs fed the capsicum diet had less NO production when stimulated ex vivo with LPS when compared with PBMC isolated from pigs fed the WYC-only diet. The reduction in NO concentrations by these PBMC may indicate that capsicum is effective at controlling NO production to prevent oxidative damage, but such effects need to be confirmed in vivo. The lack of differences between infected groups after $48 \mathrm{~h}$ of culture could be due to $48 \mathrm{~h}$ being too long after initial LPS stimulation to observe changes in NO production. Because we only quantified the total amount of NO produced, we cannot definitively claim that capsicum inhibited the inducible NO synthase protein directly, or if capsicum is inhibiting NO production through another route.

In conclusion, we observed minimal effects of feeding WYC and capsicum to ETEC-infected weanling pigs in terms of growth performance. Our results demonstrate that WYC and capsicum did influence characteristics of the immune system, especially with regard to profiles of T-cell populations. Although neither feed additive alone was able to alter T-cell subpopulations, the additive combination did decrease the proportions of both cytotoxic and memory T-cells. Further research is needed to investigate the mechanism by which the combination of these additives modulates the immune response, and reducing $\mathrm{T}$-cell subpopulations to determine whether they make a good alternative to antibiotics when ETEC infection occurs.

\section{LITERATURE CITED}

Almeida, J. A., N. P. Ponnuraj, J. J. Lee, P. Utterback, H. R. Gaskins, R. N. Dilger, and J. E. Pettigrew. 2014. Effects of dietary clays on performance and intestinal mucus barrier of broiler chicks challenged with salmonella enterica serovar typhimurium and on goblet cell function in vitro. Poult. Sci. 93:839-847. doi:10.3382/ps.2013-03587.

Bäumler, A. J., R. M. Tsolis, and F. Heffron. 1997. Fimbrial adhesins of Salmonella typhimurium. Role in bacterial interactions with epithelial cells. Adv. Exp. Med. Biol. 412:149-158.

Che, M. T., R. W. Johnson, K. W. Kelley, K. A. Dawson, C. A. Moran, and J. E. Pettigrew. 2008. Effects of mannan oligosaccharide and mannan rich fraction of Saccharomyces cerevisiae on production of cytokines by alveolar macrophages. J. Anim. Sci. 86(Suppl. 2):347. (Abstr.) doi:10.2527/jas.2011-4310.

Chen, Y. C., M. J. Higgins, N. A. Maas, and S. N. Murthy. 2006. DNA extraction and Escherichia coli quantification 
of anaerobically digested biosolids using the competitive touchdown PCR method. Water Res. 40:3037-3044. doi:10.1016/j.watres.2006.06.020.

Davis, M. E., C. V. Maxwekkm, E. B. Kegely, B. Z. de Rodas, K. G. Friesen, D. H. Hellwig, and R. A. Dvorak. 1999. Efficacy of mannan oligosaccharide (Bio-Mos) addition at two levels of supplemental copper on performance and immunocompetence of early-weaned pigs. J. Anim. Sci. 77(Suppl. 1):63. (Abstr.)

DebRoy, C., and C. W. Maddox. 2001. Identification of virulence attributes of gastrointestinal Escherichia coli isolates of veterinary significance. Anim. Health Res. Rev. 2:129-140.

Fairbrother, J. M., É. Nadeau, and C. L. Gyles. 2005. Escherichia coli in postweaning diarrhea in pigs: an uptake on bacterial types, pathogenesis, and prevention strategies. Anim. Health Res. Rev. 6:17-39.

Firon, N., I. Ofek, and N. Sharon. 1983. Carbohydrate specificity of the surface lectins of Escherichia coli, Klebsiella pneumoniae, and Salmonella typhimurium. Carbohydr. Res. 120:235-249.

Gallois, M., H. J. Rothkötter, M. Bailey, C. R. Stokes, and I. P. Oswald. 2009. Natural alternatives to in-feed antibiotics in pig production: can immunomodulators play a role? Animal 3:1644-1661. doi:10.1017/S1751731109004236.

Hammer, K. A., C. F. Carson, and T. V. Riley. 1999. Antimicrobial activity of essential oils and other plant extracts. J. Appl. Microbiol. 86:985-990.

Ivers, D. J., and T. L. Veum. 2012. Effect of graded levels of niacin supplementation of a semipurified diet on energy and nitrogen balance, growth performance, diarrhea occurrence, and niacin metabolite excretion by growing swine. J. Anim. Sci. 90:282-288. doi:10.2527/jas.2011-4035.

Kariyama, R., R. Mitsuhata, J. W. Chow, D. B. Clewell, and H. Kumon. 2000. Simple and reliable multiplex PCR assay for surveillance isolates of vancomycin-resistant enterococci. J. Clin. Microbiol. 38:3092-3095.

Kim, M. H., S. G. Kang, J. H. Park, M. Yanagisawa, and C. H. Kim. 2013. Short-chain fatty acids activate GPR41 and GPR43 on intestinal epithelial cells to promote inflammatory responses in mice. Gastroenterology 145:396-406. e1. doi:10.1053/j.gastro.2013.04.056.

King, R. H. and J. R. Pluske. 2003. Nutritional management of the pig in preparation for weaning. In: J. R. Pluske, J. Le Dividich, and M. W. A. Verstegen, editors, Weaning the Pig: Concepts and Consequences. Wageningen Academic Publishers, Wageningen, NL. p. 37-51.

Kogan, G. and A. Kocher. 2007. Role of yeast cell wall polysaccharides in pig nutrition and health protection. Livest. Sci. 109:161-165. doi:10.1016/j.livsci.2007.01.134

Korhonen, R., A. Lahti, H. Kankaanranta, and E. Moilanen. 2005. Nitric oxide production and signaling in inflammation. Curr. Drug Targets. Inflamm. Allergy 4:471-479.

Kornegay, E. T., D. Rhein-Welker, M. D. Lindemann, and C. M. Wood. 1995. Performance and nutrient digestibility in weanling pigs as influenced by yeast culture additions to starter diets containing dried whey or one of two fiber sources. J. Anim. Sci. 73:1381-1389.

Le Bon, M., H. E. Davies, C. Glynn, C. Thompson, M. Madden, J. Wiseman, C. E. R. Dodd, L. Hurdidge, G. Payne, Y. Le Treut, et al. 2010. Influence of probiotics on gut health in the weaned pig. Livest. Sci. 133:179-181. doi:10.1016/j.livsci.2010.06.058
Lee, H. S., B. S. Kim, and M. K. Kim. 2002. Suppression effect of Cinnamomum cassia bark-derived component on nitric oxide synthase. J. Agric. Food Chem. 50: 7700-7703.

Lee, H. S., S. H. Lee, Y. S. Kim, C. G. Song, and M. K. Kim. 2000. Effect of oriental medicinal plants on nitric oxide synthase activity. Food Sci. Biotechnol. 9: 77-82.

LeMieux, F. M., L. L. Southern, and T. D. Bidner. 2003. Effect of mannan oligosaccharides on growth performance of weanling pigs. J. Anim. Sci. 81:2482-2487. doi:10.2527/2 003.81102482x.

Li, J., D. F. Li, J. J. Xing, Z. B. Cheng, and C. H. Lai. 2006. Effects of beta-glucan extracted from Saccharomyces cerevisiae on growth performance, and immunological and somatotropic responses of pigs challenged with Escherichia Coli lipopolysaccharide. J. Anim. Sci. 84:2374-2381. doi:10.2527/jas.2004-541.

Li, W., R. Tsubouchi, S. Qiao, M. Haneda, K. Murakami, and M. Yoshino. 2006. Inhibitory action of eugenol compounds on the production of nitric oxide in RAW264.7 macrophages. Biomed. Res. 27:69-74.

Liu, Y., T. M. Che, D. Bravo, and J. E. Pettigrew. 2012. Antiinflammatory effects of several plant extracts on porcine alveolar macrophages in vitro. J. Anim. Sci. 90:2774-2783. doi:10.2527/jas.2011-4304

Liu, Y., J. Song, T. M. Che, J. A. S. Almeida, J. J. Lee, D. Bravo, C. W. Maddox, and J. E. Pettigrew. 2013. Dietary plant extracts alleviate diarrhea and alter immune responses of weaned pigs experimentally infected with a pathogenic Escherichia coli. J. Anim. Sci. 91:5294-5306. doi:10.2527/ jas.2012-6194

Maslowski, K. M., A. T. Vieira, A. Ng, J. Kranich, F. Sierro, D. Yu, H. C. Schilter, M. S. Rolph, F. Mackay, D. Artis, et al. 2009. Regulation of inflammatory responses by gut microbiota and chemoattractant receptor GPR43. Nature 461:1282-1286. doi:10.1038/nature08530.

McCracken, B. A., M. E. Spurlock, M. A. Roos, F. A. Zuckermann, and H. R. Gaskins. 1999. Weaning anorexia may contribute to local inflammation in the piglet small intestine. J. Nutr. 129:613-619. doi:10.1093/ jn/129.3.613.

Moeser, A. J., K. A. Ryan, P. K. Nighot, and A. T. Blikslager. 2007. Gastrointestinal dysfunction induced by early weaning is attenuated by delayed weaning and mast cell blockade in pigs. Am. J. Physiol. Gastrointest. Liver Physiol. 293:G413-G421. doi:10.1152/ajpgi.00304.2006. National Research Council (NRC). 2012. Nutrient Requirements of Swine, 11th ed. National Academies Press, Washington, DC, USA.

van der Peet-Schweing, C. M. C., A. J. M. Jansman, H. Smidt, and I. Yoon. 2007. Effects of yeast culture on performance, gut integrity, and blood cell composition of weanling pigs. J. Anim. Sci. 85:3099-3109. doi:10.2527/jas.2007-0110

Sads, O. R. and G. Bilkei. 2003. The effect of oregano and vaccination against Glasser's disease and pathogenic Escherichia coli on post-weaning performance of pigs. Ir. Vet. J. 56:611-615.

Shoba, F. G., and M. Thomas. 2001. Study of antidiarrhoeal activity of four medicinal plants in castor-oil induced diarrhoea. J. Ethnopharmacol. 76:73-76.

Spurlock, M. E. 1997. Regulation of metabolism and growth during immune challenge: an overview of cytokine function. J. Anim. Sci. 75:1773-1783. 
Vieira, A. T., M. M. Teixeira, and F. S. Martins. 2013. The role of probiotics and prebiotics in inducing gut immunity. Front. Immunol. 4:445. doi:10.3389/fimmu.2013.00445.

White, L. A., M. C. Newman, G. L. Cromwell, and M. D. Lindemann. 2002. Brewers dried yeast as a source of mannan oligosaccharides for weanling pigs. J. Anim. Sci. 80:2619-2628.
Widowski, T. M., S. E. Curtis, and C. N. Graves. 1989. The neutrophil:lymphocyte ratio in pigs fed cortisol. Can. J. Anim. Sci. 69:501-504.

Yaqoob, P. and P. C. Calder. 2011. The immune and inflammatory systems. In: S. A. Lanham-New, I.A. Macdonald, and H.M. Roche, editors, Nutrition and metabolism, 2nd ed. The Nutritional Society, West Sussex, United Kingdom. p. 312-338. 